\title{
NOTA \\ LA LINGÜÍSTICA DEL TEXTO Y LA PRAGMÁTICA LINGÜÍSTICA
}

\author{
Gloria Guerrero Ramos \\ (Universidad de Málaga)
}

La lingüística del texto o textual comenzó a desarrollarse como tal en los últimos años de la década de los sesenta y desde entonces ha conocido una evolución rápida, centrada sobre todo en aspectos teóricos más que en aplicaciones concretas. Esta teoría viene a cubrir el vacío dejado por la lingüística oracional, cuya limitación al dominio de la oración contrasta con la hipótesis de partida de la lingüística textual, según la cual no hablamos por frases sino por textos y «todas las unidades lingüisticas regulan su interacción operativa según el plan textual en que aparecen insertas» ${ }^{1}$.

Se entiende por texto una unidad de dimensiones variables, caracterizada, en términos generales, por una autonomía total de la que carecen las unidades de niveles distintos (palabra, frase, oración) con dependencia de unidades jerárquicas superiores. La delimitación del tex to depende de «la intención comunicativa del hablante, de lo que él conciba y quiera comunicar, como conjunto de unidades lingüísticas vinculadas en un conglomerado total de intención comunicativa» ${ }^{2}$.

La lingüística del texto puede aparecer como desarrollo ulterior de modelos aplicados a la lingüística oracional que se extiende a realidades del discurso no abarcadas por aquella. Es el caso del modelo propuesto por Teun A. Van Dijk en Some Aspects of Text Grammar, aparecido en 1972, quien, desde el seno de la gramática generativa transformacional, extiende conceptos claves tales como competencia, estructura profunda, estructura superficial, al componente textual. Considera necesario postular una estructura subyacente para los textos de las

1 ALBADALEJO, T. y GARCÍA BERRIO, A., «La lingüística del texto», en ABAD, F. y GARCIA BERRIO, A., Introducción a la lingüística, Madrid, 1983, p. 217.

2 GARCIA BERRIO, A. y VERA LUJÁN, A., Fundamentos de teoría lingüistica, Málaga, 1977, p. 172 . 
lenguas naturales, basándose en razones de carácter empírico y psicológico, puesto que es difícil concebir que el hablante pueda producir y entender textos complejos como un todo coherente sin un programa o estrategia subyacente. Para él, la estructura subyacente textual o macroestructura - que dará cuenta de la coherencia del discurso - será de carácter lógico-semántico. Por esta razón, considera Van Dijk que la semántica generativa puede ser, en muchos aspectos, un modelo adecuado para abordar la teorización de macroestructuras textuales.

Prescindiendo de las diferencias que se pueden observar en las distintas derivaciones, la linguística del texto ha de ocuparse de la competencia textual, es decir, de los conocimientos linguísticos de carácter textual que posee el hablante, conocimientos que le permiten distinguir textos gramaticales de tex tos no gramaticales, producir, resumir, calificar textos, etc. En definitiva, «la denominada lingüística del texto, en nuestros días supone en muchos de sus aspectos, un resumen o hasta cierto punto 'cajón de sastre' en la que se articulan, dentro de una propia sistemática formal y estática post-chomskyana, las más variadas tendencias de tipo pragmático, semántico-lógico, sociológico, psicológico, crítico-literario, etc.» ${ }^{3}$.

El cometido específico de la lingüística del texto comienza allí donde los modelos de lingüística oracional se muestran inadecuados en el tratamiento de la realidad lingüística. Sin embargo, la lingüística textual podría concebirse como lingüística total, en la que se integrasen aquellos modelos que se ocupan de aspectos puramente oracionales, dado que el texto es la unidad lingüística que engloba todas las demás ${ }^{4}$.

A partir del reconocimiento del texto como unidad lingüística máxima, se han ido elaborando distintos modelos que parten del texto como fundamento; dichos modelos, sometidos a un constante enriquecimiento y desarrollo, se ven sujetos a continuas reelaboraciones, aspecto ligado a la esencia del método hipotético-deductivo que, desde sus inicios, fue asumido por la lingüística textual. Las investigaciones lingüístico-textuales de Van Dijk, Petöfi o Schmidt han ido dibujando, cada vez con más nitidez, una imagen del texto como ámbito lingüístico-comunicativo que aparece como un logro fundamental de la teoría gramatical. Ciertamente, aunque esta serie de trabajos ha incidido sobre gran número de aspectos particulares del funcionamiento de lo textual, la imagen global de la textualidad es, sin embargo, de una enorme complejidad en sus procesos funcionales, de forma que, contempladas estas investigaciones en su estado actual, reflejan cierta provisionalidad, que aguarda un desarrollo más

3 MARTINEZ ARNALDOS, M., Lenguaje, texto y mass-media. Aproximación a una encrucijada, Univ. de Murcia, 1990, p. 54.

4 ALBADALEJO, T. y GARCÍA BERRIO, A., «La lingüística del texto», art. cit., p. 220. 
pormenorizado de los diferentes modelos textuales. Hay autores como Bertinetto que llegan, incluso, a afirmar «che non può esistire una lingüística del testo ... $)^{5}$.

Por esta razón no nos parece conveniente partir de un modelo lingüísticotextual para la descripción de una lengua, si bien reconocemos que la noción de texto se revela como un recurso de importancia singular en gran número de cuestiones conectadas con el funcionamiento de otros niveles lingüísticos que pueden adquirir un sentido pleno sólo a la luz de las exigencias de funcionamiento del nivel textual. Así, por ejemplo, aspectos tales como la posición del acento en el enunciado, las relaciones causales entre enunciados que se suceden sin conjunciones, la sucesión de los tiempos, la selección del artículo, las anáforas y catáforas, la estructuración en tema y rema, y otros mecanismos interpretados como formas de coherencia textual, que sólo pueden ser abordados a partir de la consideración del tex to como unidad.

Por otra parte, como ha señalado Tomás Albadalejo, «un modelo lingüísticotextual ha de estudiar los aspectos pragmáticos del lenguaje, para lo cual es de gran utilidad que cuente con un componente pragmático» ${ }^{6}$.

Sin embargo, el objeto de la pragmática lingüística, hasta ahora, no está claramente definido. Existe especial confusión en su delimitación frente a la lingüística del texto y a la teoría de la comunicación. Ni siquiera existe una definición de pragmática ya que, como ha señalado Schlieben-Lange, llama la atención «que en los escritos programáticos de Dieter Wunderlich, que puede considerarse como representante fundamental de la pragmática lingüística en Alemania, se evite expresamente una defínición de pragmática ${ }^{7}$. Pero el problema radica en la necesidad de definición ${ }^{8}$.

Es bien sabido ya, por otro lado, que la pragmática constituye el tercer componente de la tríada que Morris retoma de Peirce, cuyos otros dos son la

5 BERTINETTO, P.M., «I paradossi della nozione di testo», en A.A.V.V., Teoría e analisi del testo, Padua, 1981, p. 21.

- ALBADAlEJO MAYORDOMO, T., «Componente pragmático, componente de representación y modelo lingüústico-textual», en BERNÁRDEZ, E. (comp.), Lingüística del texto, Madrid, 1987, pp. 179-228; tomamos la cita de la p. 181.

7 SCHLIEBEN-LANGE, B., Pragmática lingüística, Madrid, 1987, p. 11. Para las posibles definiciones de pragmática véase LEVINSON, S.C., Pragmática, (1983), Barcelona, 1989.

p. 22.

Cfr. REYES, G., La pragmática lingüística. El estudio del uso del lenguaje, Barcelona, 1990,

9 Un estudio en el que se analiza la evolución de pragmática lingüística puede verse en SCHLIEBEN-LANGE, B., op. cit., y en REYES, G., op. cit.; una visión general e introductoria se halla en el estudio de HERNÁNDEZ SACRISTÁN, C., «Pragmática», en LÓPEZ, Á. et al., Lingüistica general..., ya citado, pp. 243-272. Debe consultarse además para este tema, en concreto, entre otros: DIJK, T.A. van, «La pragmática de la comunicación literaria», en MAYORAL, J.A. (comp.), Pragmática de la comunicación literaria, Madrid, 1987, pp. 171-194; DIJK, T.A. van, "Pragmática: texto, actos de habla y contexto», en La ciencia del texto. Un enfoque interdisciplinario, Barcelona, 1989, pp. 77-107; CARÓN, J., Las regulaciones del discurso. Psicolingǘistica y pragmática del lenguaje, Madrid, 1989. 
sintaxis y la semántica, constituyendo una teoría semiótica? . Así «mientras que la sintaxis especifica en qué condiciones y según cuáles reglas los enunciados están 'bien formados' y la semántica indica las condiciones para que los enunciados sean 'interpretables' (tanto en lo relativo al significado como a la referencia), a la pragmática se le adjudica la tarea de ocuparse de las condiciones bajo las que las manifestaciones lingüisticas son aceptables (acceptable), apropiadas u oportunas (appropriate) $\gg^{10}$.

En definitiva, la pragmática estudia las condiciones y reglas para la idoneidad de enunciados (actos de habla) ${ }^{11}$ expresados por el hablante en una situación comunicativa (contexto) determinada, es decir, se ocupa de la relación entre el lenguaje y el hablante.

Si nos remontamos a la distinción saussureana entre linguística de la lengua y lingüística del habla y, en especial, a sus discípulos de la Escuela de Ginebra, los cuales postulaban explícitamente ya una lingüística del habla ${ }^{12}$, comprobaremos «que ya se hacía pragmática mucho antes de que se concibiera una disciplina dedicada a descubrir los principios que guían la comunicación verbal [...] Pero la lingüística ha emprendido hace sólo pocos años el estudio sistemático del uso linguístico, y no sin retrocesos, dudas y contrariedades, quizá porque el dominio de estudio es demasiado amplio y compartido por otras ciencias» ${ }^{13}$.

La pragmática, pues, debe hacerse un lugar en la lingüística y también junto al grupo de disciplinas que estudian la comunicación humana. Pero, sobre todo, debe buscar su objeto de estudio, un objeto fijo, homogéneo y bien acotado ${ }^{14}$. Entendemos que debe ser complementaria de la gramática (sintaxis y semántica) en un paradigma formal-funcional ${ }^{15}$. Debemos considerarla como perspectiva «que puede aplicarse a cualquier aspecto de la estructura del lenguaje, pues cualquier aspecto tiene alguna función relacionada con la comunicación $»^{16}$.

10 DUJK, T.A. van, «Pragmática...», art. cit., pp. 80-81.

1 Véase al respecto AUSTIN, J.L., Cómo hacer cosas con palabras. Palabras y acciones, (1962), Barcelona, 1982.

${ }_{12} \mathrm{Cfr}$. COSERIU, E., «Sistema, norma y habla», en Teoría del lenguaje y lingüística general, Madrid, $1989^{3}$, pp. 11-113.

13 REYES, G., op. cit., p. 18.

${ }_{14}$ Cfr. REYES, G., op. cit., p. 23.

is Véanse los postulados formulados al respecto por LEECH, G., Principles of pragmatics, Londres-Nueva York, 1983.

16 REYES, G., op. cit., p. 41. 